\title{
THE INFLUENCE OF THE PASSIVE EARTH PRESSURE AND OTHER FACTORS ON THE STABILITY OF THE UNDERGROUND MASONRY VAULTS OF THE PARIS METRO
}

\author{
O. MORENO REGAN ${ }^{1}$, E. BOURGEOIS ${ }^{2}$, JF. DOUROUX ${ }^{3}$ AND A. DESBORDES $^{3}$ \\ 1 setec tpi
}

Immeuble Central Seine - 42-52 quai de la Rapée 75583 Paris, France

e-mail: omar.moreno-regan@ setec.com,www.setec.fr/en/

${ }^{2}$ COSYS-LISIS, Univ Gustave Eiffel, IFSTTAR,

5, boulevard Descartes, Champs sur Marne, F-77454 Marne-la-Vallée, France

email: emmanuel.bourgeois@ univ-eiffel.fr,www.univ-gustave-eiffel.fr/en/

${ }^{3}$ RATP
50 Rue Roger Salengro, 94724 Fontenay-sous-bois, France
e-mail: jean-francois.douroux@ @ ratp.fr, alain.desbordes@ ratp.fr
www.ratp.fr/en

Keywords: Masonry, Damage, Tunnel, Vault, Metro, FEM

\begin{abstract}
This paper presents an analysis of the behavior of masonry tunnel vaults of the Paris metro when their state of equilibrium is altered. These tunnels were built with a masonry vault combined with sidewalls and a slab made of unreinforced concrete. The main case studied here is that of the spreading of the vault's supports as a result of nearby construction works. Numerical computations are carried out using a specifically developed model for the masonry that combines a homogenization technique with damage models. An interface between the tunnel and the ground allows the study of the soil-structure interaction. The proposed model identifies the possible hinging failure mechanisms and their configuration based on the horizontal displacements and the geometry of the structure. Several other simpler constitutive laws for the masonry are also used and then compared with the proposed model. An analysis on the loss of the passive earth pressure and the deformation of the structure are also provided. Based on the numerical simulations made and real measurements, it was observed that the studied underground masonry vaults may withstand several centimeters of support spreading.
\end{abstract}

\section{INTRODUCTION}

The Paris subway system, operated by the Régie Autonome des Transports Parisiens (RATP), has sixteen lines and carries about 5 million passengers daily. The infrastructure is mostly underground and was built predominantly in the early twentieth century. About $85 \%$ of the tunnels comprise a masonry vault. The typical section adopted for the tunnels was built with a masonry vault (blocks of gritstone or meulière stone and mortar) and unreinforced concrete sidewalls and ground slab. More details can be found in [1] and [2]. To evaluate the 
serviceability state of a tunnel, or the impact of nearby civil engineering works carried out in the vicinity, it is necessary to predict the behavior of the masonry vault and the concrete walls and slab using advanced numerical tools. It is then possible to assess any possible damage to the existing structure. Although the modelling of historical masonry structures has been the subject of many scientific publications [1], there are few references on modelling masonry tunnels. Some studies have been carried out using elastic FEM analysis or limit analysis [1].

This study follows up the model that we developed for masonry vaults [3] and the experimental campaign [2] needed to characterize the materials. This model, as will be discussed later on, uses a homogenization technique and damage mechanics. The issue examined in this paper is that of the spreading of the vault's supports as a result of nearby construction works. Results of the numerical simulation are compared with in situ measurements. The proposed model provides a realistic and effective way to analyze the behavior of masonry vaults and gives access to the deformation state of the structure thus allowing the serviceability state and failure load to be evaluated.

\section{DESCRIPTION OF THE CASE STUDY}

The study deals with the station "Mairie d'Ivry", the southern terminus of the line 7 of the Paris Metro. The three-lane tunnel that forms the station is about $105 \mathrm{~m}$ long and it was built with a semi-circular shaped masonry vault supported by two unreinforced concrete sidewalls, bound by a curved unreinforced concrete ground slab. Dimensions are shown in Figure 1 and

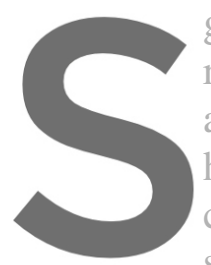
geology in Figure 2. records, the method of as bored piles. Excavation heading. Once the sidewalls construction of the masonry vault was carried section (core and bottom) allowed the realizat several problems were reported, caused by swelling of the clay layer.

Register for free at https//www.scipedia.com to download the version without the watermark

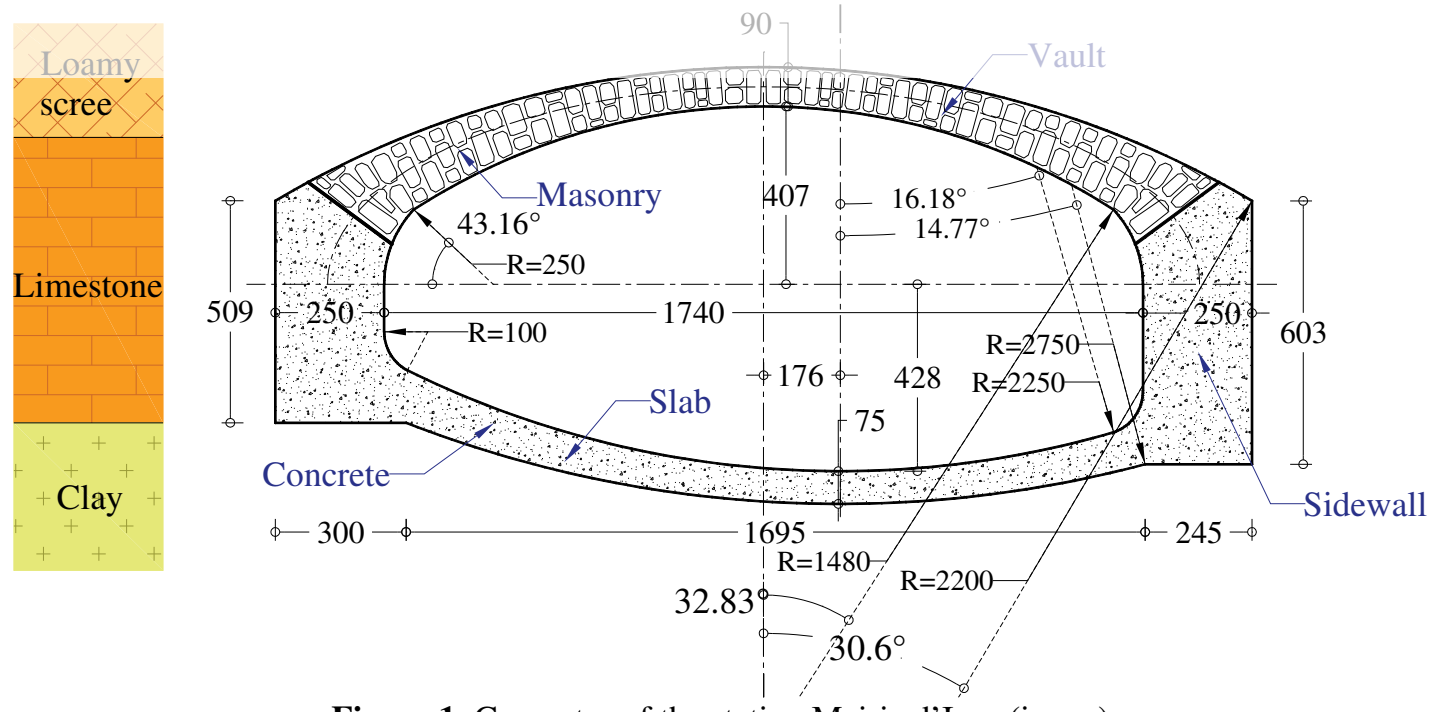

Figure 1: Geometry of the station Mairie d'Ivry (in $\mathrm{cm}$ ) 
Several decades later, the construction of a group of buildings near the station required to perform a deep excavation (Figure 2), which was carried out in a short period of time in 1983.

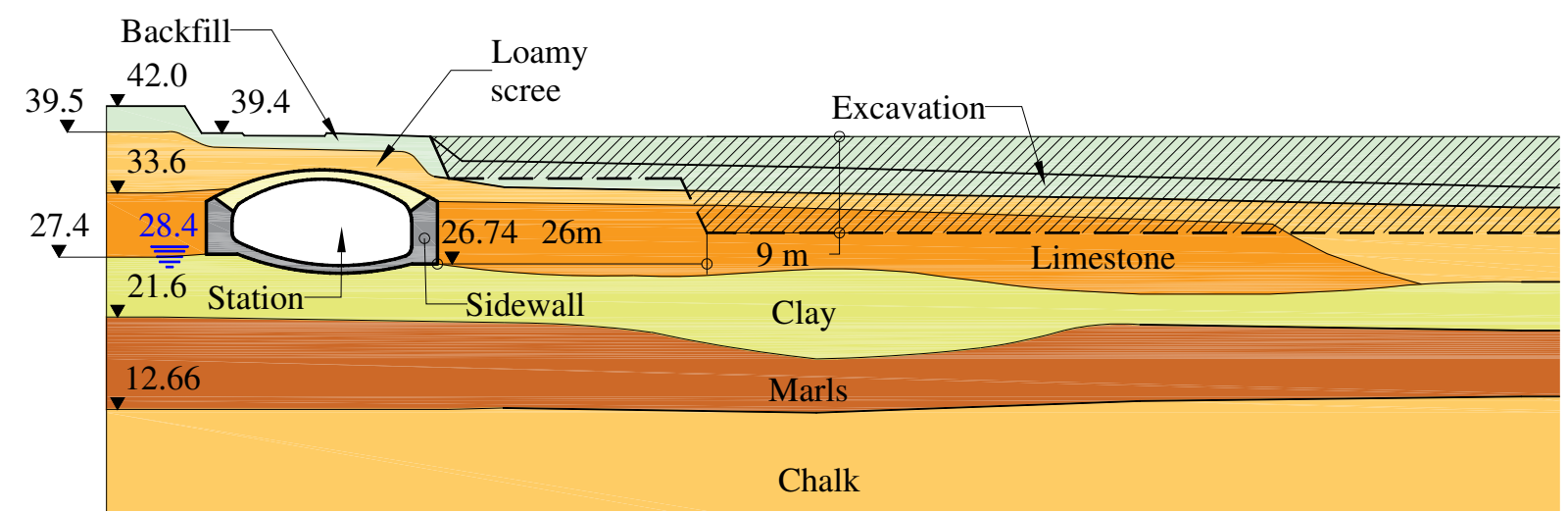

Figure 2: Geology and construction works near the station "Mairie d'Ivry"

Immediately after, numerous structural problems were reported in the station: cracks at the crown and slab (Figure 3), water infiltrations, dislodged tiles, etc. These problems led to the setup of a series of measurements that revealed the subsidence of the masonry vault, the increasing distance between sidewalls and the uplift of the slab. Measurements were taken from 1984 to 2007 (see Figure 6). Several hypotheses were suggested to explain these observations: the decompression and $\mathrm{e}$ decrease of the passive needed to ensure stabili the modification of their right sidewall, the left sid

In order to stabilize the deformations of
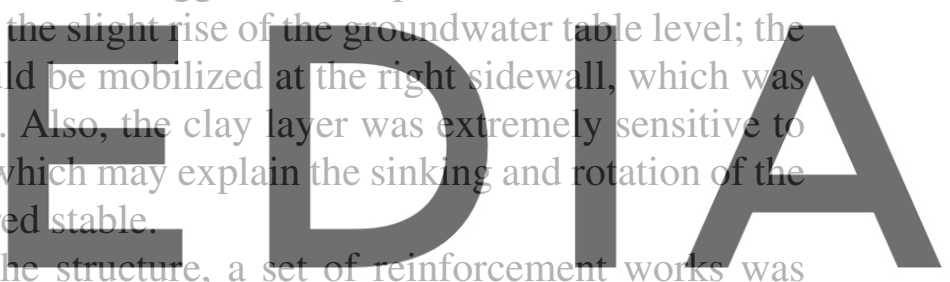
carried out in the tunnel (Figure 3): in 1987 a series of micropiles were installed alongside the

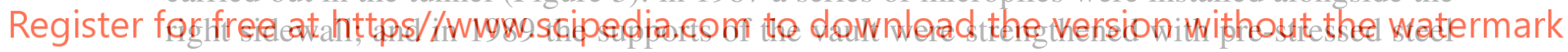
tie rods, reducing in this way the thrust of the vault. The tie rods can be seen to this day. Details on the reinforcements can be found in Appendix $A$ and [4].
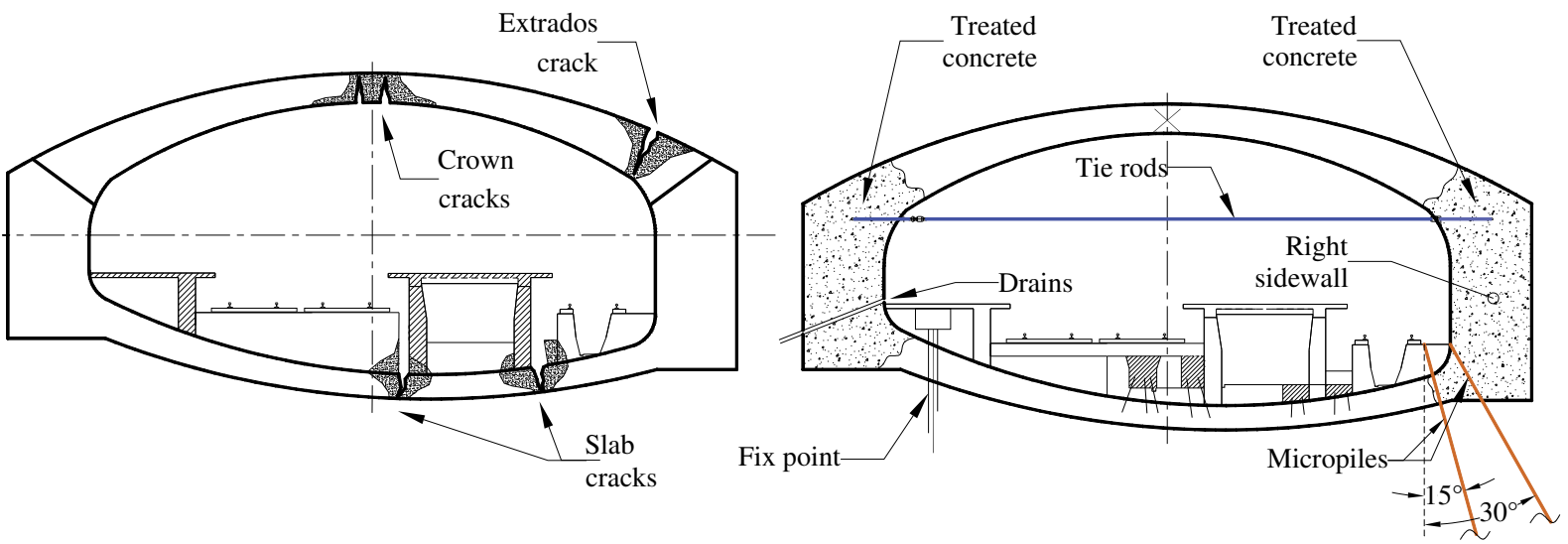

Figure 3: Visible cracks and reinforcement works at the station [4] 


\section{MODELLING STRATEGY}

\subsection{General considerations}

The objective of the study is to reproduce in the most accurate possible way the observed behavior of the tunnel. To this end, a two-dimensional finite element model was built to study the tunnel. Masonry was studied with a specific homogenization-damage model. Soil-structure interaction was modelled through an interface. This model incorporates then several nonlinear material behaviors: tunnel structure, surrounding soil and interface.

In order to study the tunnel problem in 2D we adopted the so-called convergenceconfinement method [5][6] to take into account the three-dimensional aspects of the tunneling process in a plane strain analysis. The construction of the tunnel is controlled using a confinement loss parameter $\lambda$ that ranges from 0 (perfect confinement) to 1 (no confinement). More details are given in $\$ 3.4$. The groundwater table was modelled implicitly: ground layers below this level were modeled with their effective weight; water pressure was applied to the tunnel assuming that the structure is completely impervious. Stiffness of the initial wood support used to build the tunnel is not taken into account: in the modeling we consider that it no longer exists, and the earth pressure is directly applied to the masonry lining. The calculation was carried out in plane strain and in effective stress.

\subsection{Numerical model for the tumnel materials}
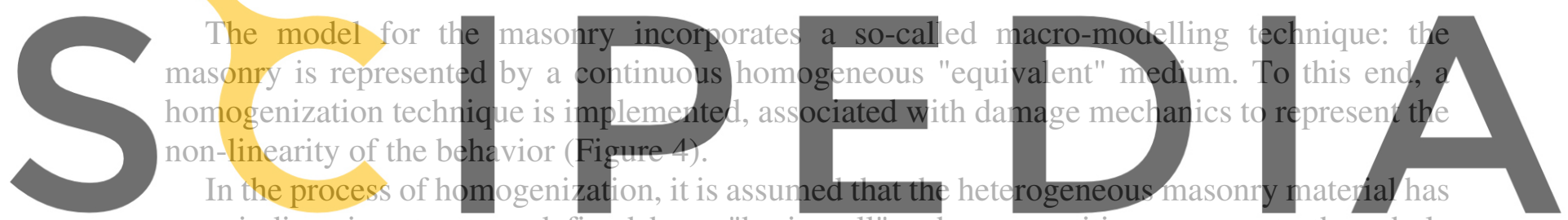

a periodic microstructure defined by a "basic cell", whose repetition represents the whole

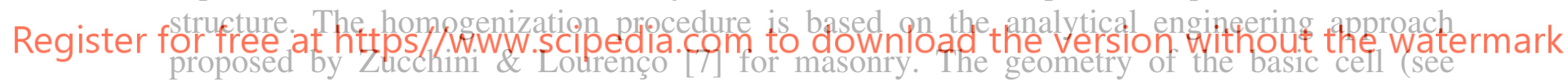
Appendix A) and the behavior of its components, i.e. blocks and joints, are used to derive the orthotropic constitutive law of the homogenized continuum. The homogenization is carried out within the thickness of the vault.

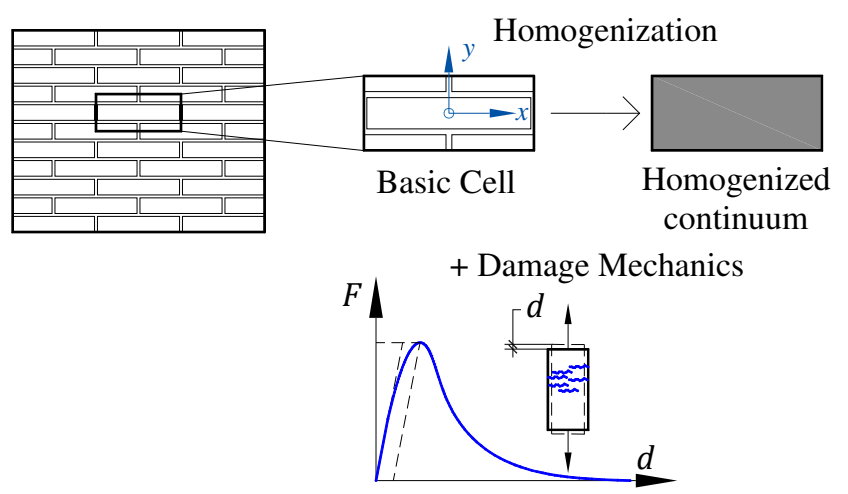

a) Numerical approach for the masonry

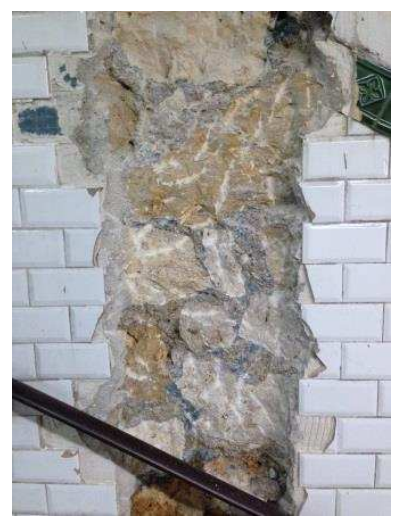

b) Typical masonry of the Paris metro tunnels

Figure 4: Homogenization of the masonry. 
Coupling homogenization and damage was carried out using the model proposed by Zucchini \& Lourenço [8]: a scalar damage variable is associated to each component of the basic cell. The problem is treated in an incremental way: under increasing load, the homogenization technique integrates the damage in each component, and consequently updates the internal stresses and elastic parameters. Here, damage in the components of the masonry is evaluated using a modified version of the isotropic damage model by Mazars [9], with an improved damage criterion and a regularization technique in tension. This damage model was also used for the unreinforced concrete of the sidewalls and ground slab. The variations of the directions of the block-mortar bond in the vault are also considered.

A thorough description of the numerical model can be found in [3]. This coupled model will be referred to as "Damage Model" hereafter. The constitutive law for masonry and concrete was implemented in the finite element code CESAR-LCPC v6 (Solver 6.2.14).

\subsection{Material properties}

The properties required for the numerical model are presented in Appendix A. Masonry's mortar and meulière stone properties led to the following homogenized properties: elastic moduli $E_{y}=10150 \mathrm{MPa}, E_{x}=14620 \mathrm{MPa}$, and Poisson's ratio $v_{x y}=0.2$ (see Figure 4a). Concrete elastic properties for the sidewall and the slab are: $E=8500 \mathrm{MPa}$ and $v=0.21$. Both set of mechanical properties are issued from [2]. The surrounding soil is made up of four layers, modeled with a linear elastic-perfectly plastic model with Mohr-Coulomb criterion. The

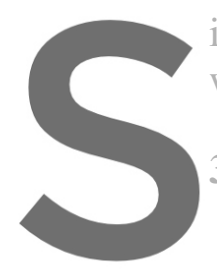

interface between the tunnel and the soil is modeled with a n
were derived from the soil mechanical properties. Details are
3.4 Initial stress in the masonry vault
In the numerical simulation, the estimation of the initial s

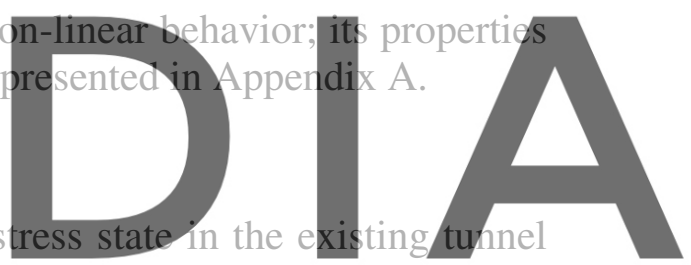

might be a complicated matter. Indeed, the initial stresses in the masonry lining might depend

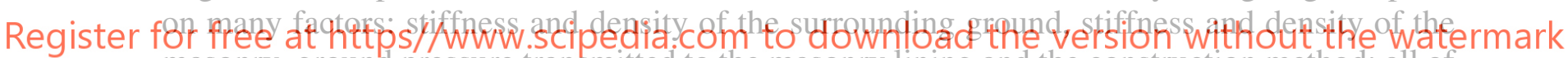
masonry, ground pressure transmitted to the masonry lining and the construction method; all of these are known only with a certain level of certainty and must be reproduced in the model. Of course, ideally, we would use in situ stress measurements in the structure [1]. In most cases though, in situ measurements are not available. What we propose here is a trial-error approach in order to produce a reasonable stress state in the vault.

As stated in $\S 3.1$, when using the chosen approach, a confinement loss parameter $\lambda$ must be introduced. Some methods have been proposed in the literature [5][6] to calculate $\lambda$ for circular tunnels with ground isotropic stress field. Nevertheless, in our study we will introduce a value of $\lambda$ in such a way that the thrust line position in the structure lies within a distance inferior to $0.3 h$ from the mean line (see Figure 5), with $h$ the height of the cross-section. This hypothesis comes from the ultimate limit state verification of unreinforced concrete tunnels [10]. This approach is accurate enough since some similar hypotheses were used when the masonry vaults were conceived [1]. The thrust line here is no other than the eccentricity $e$ of the resultant force:

$$
e=M / N
$$

where $M$ is the bending moment and $N$ the normal force. The internal forces $M$ and $N$ are calculated in each normal section to the mean line integrating numerically the normal stresses, 
assuming elastic behavior for the structure. Taken into account the masonry and soil properties, as well as the construction process (see Table 1), a satisfactory initial thrust in vault is obtained with $\lambda=0.3$ as illustrated in Figure 5 .

It is important to notice that given the construction method, the masonry vault takes direct support on the sidewalls, and these transmit the thrust of the vault to the ground. The soil next to the sidewall is thus compressed and it is found in passive conditions.

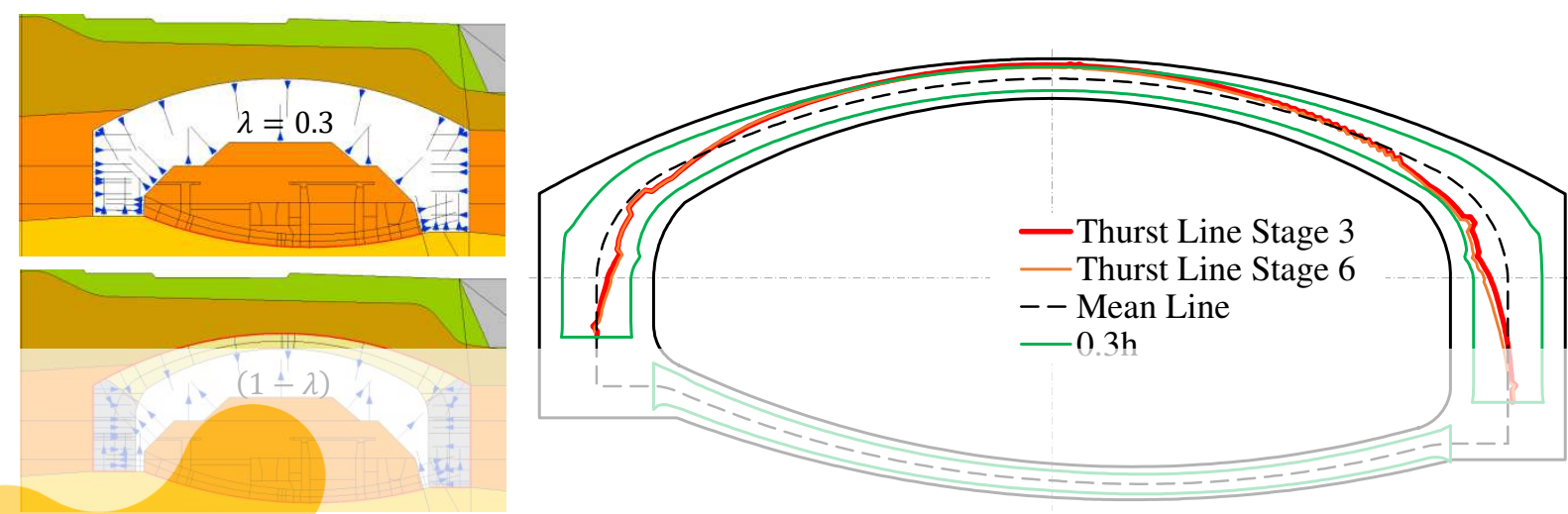

Figure 5: Initial thrust lines in the masonry vault (elastic calculation).

\subsection{Modelling stages}
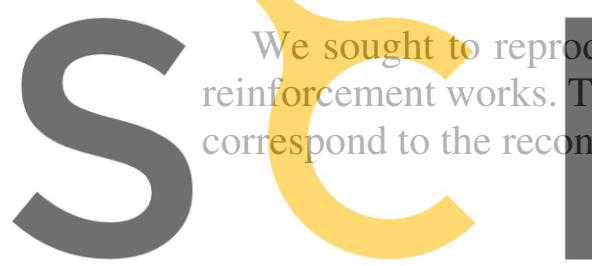
reinforcement works. T correspond to the reconst

Stage Description

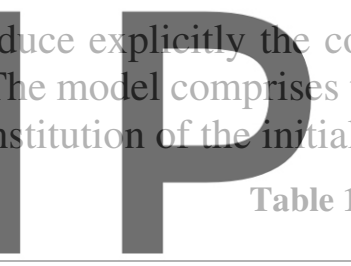

Loads

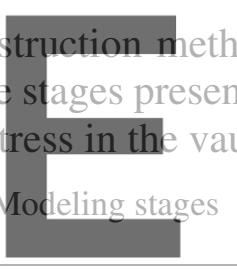

at described in $\$ 2$ as
alt discussed in section

Comments

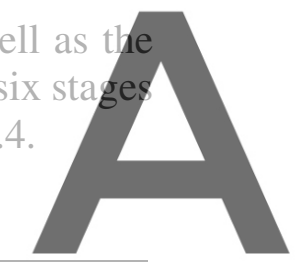

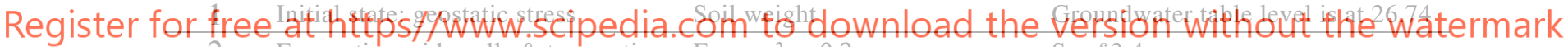

\begin{tabular}{clll}
2 & Excavation: sidewalls \& top section & Forces $\lambda=0.3$ & See $\$ 3.4$ \\
\hline 3 & "Construction": vault and sidewalls & Forces $(1-\lambda) \&$ self-weight & See $\$ 3.4$ \\
\hline 4 & Excavation: core and bottom & Forces $\lambda=0.9$ & $\begin{array}{l}\text { The ground slab was executed at } \\
\text { the end, several days later }\end{array}$ \\
\hline 5 & "Construction": Ground slab & Forces $(1-\lambda) \&$ self-weight & - \\
\hline 6 & $\begin{array}{l}\text { Natural groundwater table level } \\
\text { restauration \& platform }\end{array}$ & Water pressure & $\begin{array}{l}\text { Groundwater table level is at 28.40. } \\
\text { See Figure 2 }\end{array}$ \\
\hline 7 & Nearby excavation works & Forces $\lambda=1$ & See Figure 2 \\
\hline $8 \& 9$ & Soil creep: limestone \& clay & Creep & See $\S 3.6$ \\
\hline 10 & Setting up: Micropiles & Self-weight & See Figure 3 \& Appendix A \\
\hline 11 & Soil creep: limestone \& clay & Creep & See $\S 3.6$ \\
\hline 12 & Setting up: Tie rods & $\begin{array}{l}\text { Pre-stressed force 650 kN @ } \\
2.21 \mathrm{~m}\end{array}$ & See Figure 3 \& Appendix A \\
\hline 13 & Soil creep: limestone \& clay & Creep & See $\S 3.6$ \\
\hline
\end{tabular}

\subsection{Modelling the effects of nearby construction works on the masonry tunnel}

As explained in section 2, excavation works carried out near the tunnel together with creep phenomenon on the ground produced high deformations and cracks in the structure. What we 
seek in this study is to reproduce what happened in the tunnel and show that the proposed Damage Model may correctly predict the behavior of the existing tunnel. Since the soil next to the sidewall is altered and decompressed due to the construction, it can no longer preserve its initial mechanical properties. A simple approach to simulate the deformation of the soil over time induced by the construction is used: a simplified elastic creep model together with the reduction of the shear strength properties $c$ and $\tan \varphi$ (see Tables 4) of the clay layer under the tunnel and the limestone layer next to the right sidewall. Notice that the objective here is not to give a detailed analysis of the evolution of the soil behavior through time (such a back-analysis would be artificial without proper experimental data). The properties reduction is carried throughout several stages (\$3.4). The final properties at stage 13 are given in Tables 4. Properties of the interface (clay and limestone at right sidewall) are also subjected to creep.

\section{MASONRY VAULT DEFORMATION AND DAMAGE}

The in situ convergence measurements were taken with respect to a set of points shown in Figure 6, where the modelling results are plotted in (relative displacements in relation to point 1). Given the set of assumptions taken, it can be observed that the Damage Model manages to reproduce with fair precision the measured deformations of the tunnel (Table 2). The results of simulations with an orthotropic elastic behavior are also presented for comparison. We can clearly see that an elastic calculation completely underestimates the deformations.

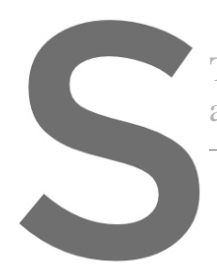

Table 2: Comparison of numerical and measured convergences ( $\mathrm{mm}$ )

Ref. Measures Damage

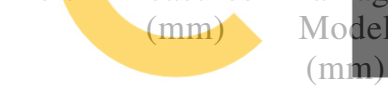
$(\mathrm{mm}) \quad(\mathrm{mm})$

$\begin{array}{llll}3-5 & -54.22 & -54.58 & -20.01\end{array}$

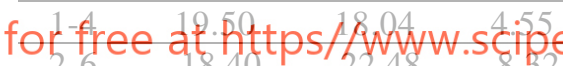

\begin{tabular}{cccc}
\hline $1-2$ & -4.0 & -3.37 & -1.69 \\
\hline $2-3$ & 5.0 & 2.31 & 0.67 \\
\hline $3-4$ & -4.0 & -3.56 & 0.63 \\
\hline $2-4$ & 13.0 & 11.04 & 4.47 \\
\hline
\end{tabular}

Remark: A positive sign means that the distance between the points increases, and negative signs indicates that it decreases.
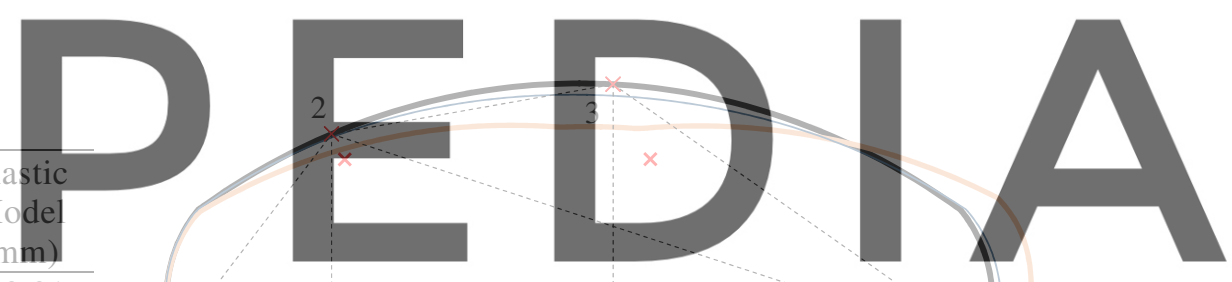

dia.com to download the version without the watermark

- Tunnel intrados

Elastic Orthotropic

$\times$ Measures

Figure 6: Deformation of the structure

Figure 7 shows the damage state in the tunnel from the numerical model. Damage at the crown of the vault is present from the initial state and evolves to the formation of three damaged zones: mid-span and vault's supports. The spreading of the vault's supports of about $20 \mathrm{~mm}$ is close to produce a hinge mechanism and therefore failure. Indeed, we observed that the loss of convergence was close in the numerical model. Hence, a mechanism will eventually form with 6 hinges: three for the vault and three for the slab. Damaged areas observed in the station (Figure 3) are reproduced with good precision by the model in the vault and the slab (Figure 7). 


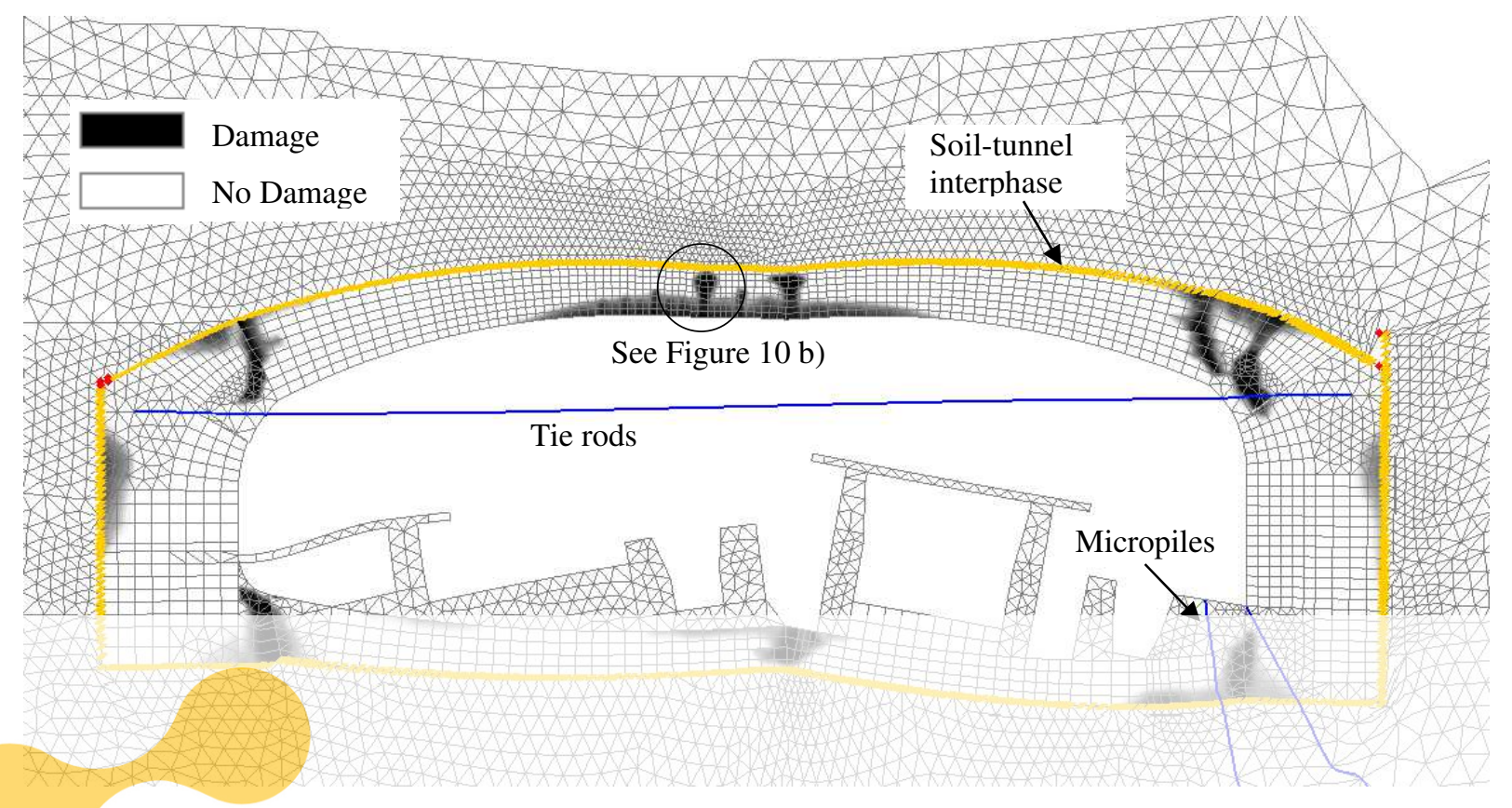

Figure 7: Modelling results: damage in the tunnel structure
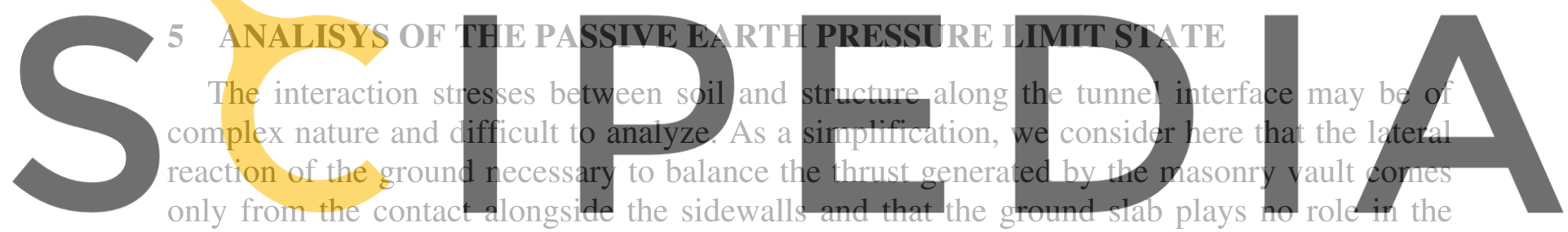

structural equilibrium. Since the modification of the equilibrium happens from the right side,

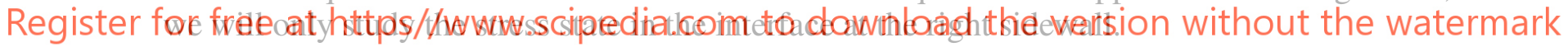

We have established that the soil next to the sidewalls is found in passive conditions (\$3.4). In order to analyze the passive state of earth pressure and its stability at the right sidewall of the tunnel, as an approximation one may use the approaches commonly used for retaining structures, particularly of those for embedded walls. The limit state of passive earth pressure in a vertical wall may be obtained from Eurocode 7[11] and its French application standard [12]. The passive earth pressure that can be mobilized $p_{\mathrm{b}, \mathrm{k}}$ is

$$
p_{\mathrm{b}, \mathrm{k}}(z)=K_{\mathrm{p}} \sigma_{\mathrm{v}}^{\prime}(z)+2 c \sqrt{K_{\mathrm{p}}} \quad \text { with } \quad K_{\mathrm{p}}=\tan ^{2}\left(\frac{\pi}{4}+\frac{\varphi}{2}\right)
$$

where $c$ is the limestone cohesion $(\$ 3.3), \sigma_{\mathrm{v}}^{\prime}$ the effective vertical stress in the ground (obtained from the FEM) and $K_{\mathrm{p}}$ the coefficient of horizontal passive earth pressure (see Appendix A). The values of $c$ and $\tan \varphi$ of are reduced progressively (\$3.6) throughout the subsequent simulation stages. Finally, the force that can be mobilized in the ground $B_{\mathrm{m}, \mathrm{k}}$ is obtained by numerical integration of $p_{\mathrm{b}, \mathrm{k}}$, calculated only alongside the right sidewall:

$$
B_{\mathrm{m}, \mathrm{k}}=\int_{\mathrm{bottom}}^{\mathrm{top}} p_{\mathrm{b}, \mathrm{k}}(z) d z
$$


Similarly, the resultant thrust generated by the vault $P_{\mathrm{t}, \mathrm{k}}$ is obtained from integrating numerically the normal and shear stresses of the interface (§3.1) alongside the sidewall:

$$
P_{\mathrm{t}, \mathrm{k}}=\sqrt{P_{x}^{2}+P_{y}^{2}} \quad \text { with } P_{x}=\int_{\text {bottom }}^{\text {top }} \sigma_{\mathrm{n}}(z) d z \text { and } P_{y}=\int_{\text {bottom }}^{\text {top }} \tau(z) d z
$$

Taken into consideration the limit state in the compressed soil suggested by the standard [12], equilibrium is found if

$$
B_{\mathrm{m}, \mathrm{d}}>P_{\mathrm{t}, \mathrm{d}} \quad \text { with } \quad B_{\mathrm{m}, \mathrm{d}}=\frac{B_{\mathrm{m}, \mathrm{k}}}{1.4} \text { and } P_{\mathrm{t}, \mathrm{d}}=1.35 P_{\mathrm{t}, \mathrm{k}}
$$

We introduce now $\Lambda$ as the loss of the passive earth pressure that can be mobilized. This quantity is defined as the reduction of $B_{\mathrm{m}, \mathrm{d}}$ with respect to a reference initial value $B_{\mathrm{m}, \mathrm{d}}^{\mathrm{ini}}$. In our case, we consider the initial resistance $B_{\mathrm{m}, \mathrm{d}}^{\mathrm{ini}}$ to be the value of $B_{\mathrm{m}, \mathrm{d}}$ from stage $6(\S 3.4)$, before the excavation carried out in 1983 , since we consider this stage as the initial equilibrium state.

We have

$$
\Lambda=1-\frac{B_{\mathrm{m}, \mathrm{d}}^{\mathrm{ini}}}{B_{\mathrm{m}, \mathrm{d}}}
$$

Analyzing now the results from the numerical model, we find that the thrust $P_{\mathrm{t}, \mathrm{d}}$ generated by the vault remains almost constant at $1 \mathrm{MN} / \mathrm{m}$ regardless of the creep, as can be seen in Figure 8a). Although the equilibrium condition (5) is nearly satisfied all of the time, Figure 8b) shows that beyond a certain threshold, convergences in the tunnel reach values larger than $10 \mathrm{~mm}$. This means that even if equilibritum is reached in the tunnel st consequences in the tunnel (cracks, water serviceability limit state may no longer be sati when a loss of about $\Lambda=55 \%$ of the passive earth pressure that can be mobilized happens; this

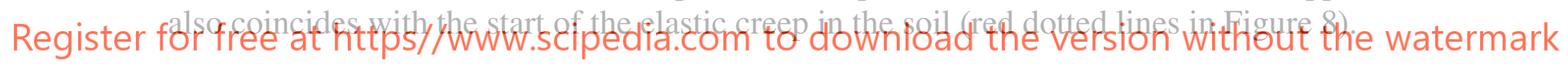

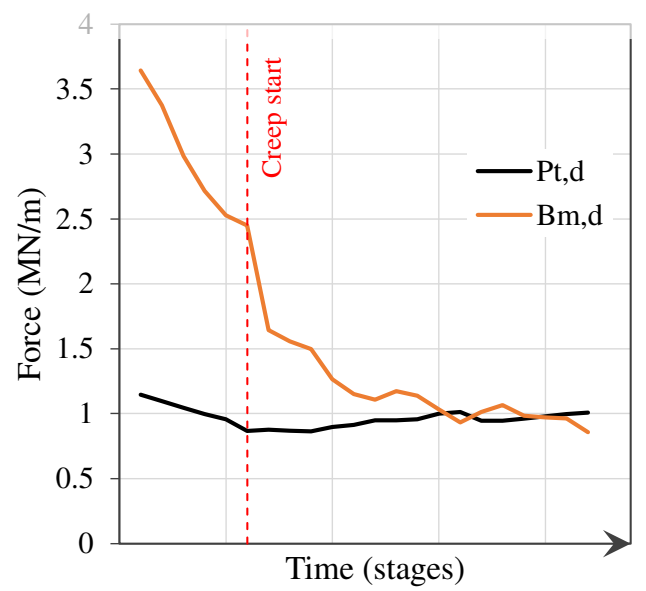

a) Evolution of vault thrust

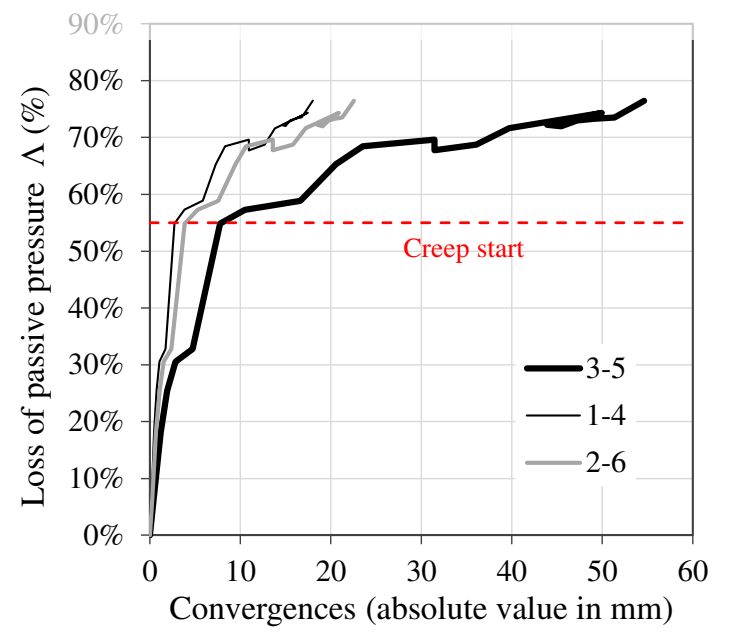

b) Tunnel deformation

Figure 8: Loss of the passive earth pressure that can be mobilized 


\section{MODELLING CHOICES FOR THE MASONRY LINING: CONSTITUTIVE LAW}

When external works are carried out nearby an existing tunnel that might affect it, most of the time displacements thresholds are imposed, in order to oversee the impact of the works on the existing structure and guarantee their safety. We will see in this section that the choice of the constitutive law for the materials comprising the tunnel's structure is of capital importance when proposing these thresholds, or simply when evaluating the impacts.

\subsection{Elastic domain}

When it comes to modeling an old masonry tunnel, in engineering practice, it is common to model it as a linear elastic isotropic material, usually with a very low elastic modulus: a typical value is about $6 \mathrm{GPa}$ [1]. This is done most likely for safety reasons: a low material stiffness can produce large displacements in the model. Nevertheless, this is inaccurate most of the time. Indeed, Figure 9 a) shows that, even with a low elastic modulus, the deformations of the tunnel remain far below the measured values (54 mm for convergence 3-5, see Table 2).

If for some reason the analysis must be carried out in the framework of elasticity for the structure, a low elastic modulus for the lining could be the most unfavorable case, when the safety criterion is measured in displacements only. However, if the objective is to verify the ultimate limit state in terms of internal forces in the structure, the most unfavorable case corresponds to a high elastic modulus of around 20-30 GPa. As it can be seen in Figure 9, a higher elastic modulus will produce higher internal forces in the structure, but lower

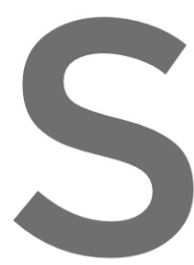
deformations.
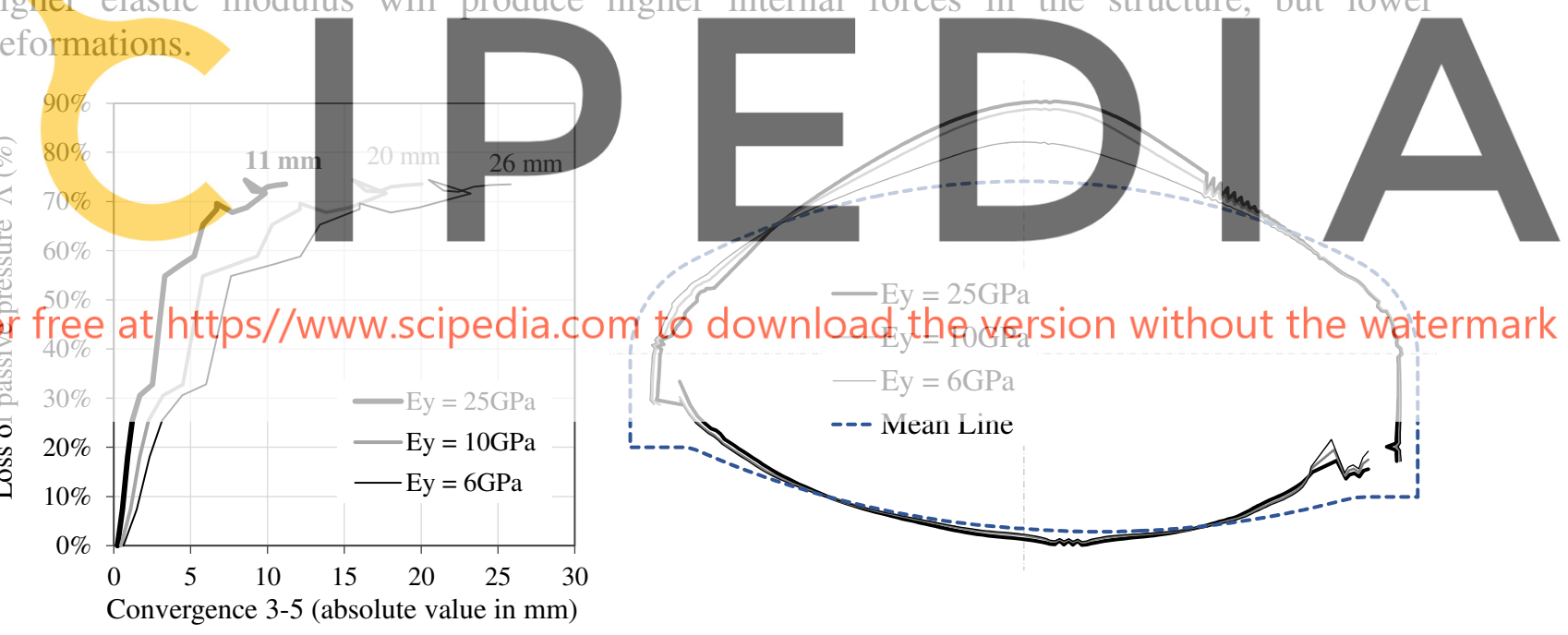

a) Tunnel deformation

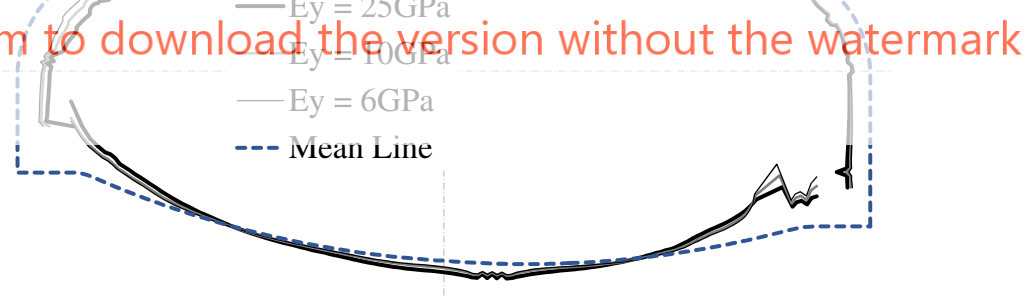

b) Internal forces: eccentricity of the resultant force (scaled)

Figure 9: Modelling results for different elastic moduli of the tunnel materials (elastic calculation)

\subsection{Nonlinear domain}

Another commonly used strategy in practice is to model the tunnel materials as a linear elastic-perfectly plastic material, using for instance the Mohr-Coulomb criterion, widely available in civil engineering software. This at least has the advantage to take into account a nonlinear behavior, even if it is not that of the quasi-brittle materials (masonry or unreinforced concrete). The central difference might be seen in the stress-strain evolutions, which are not the same. As it can be seen in Figure 10 a), the damage model is closer to the behavior found 
experimentally [2] than the elastic-plastic model. We also observe in Figure $10 \mathrm{~b}$ ) the diminution of the tensile stress at the crown crack (see Figure 7) and the concentration of the compressive stress at the top, that are not seen in the other models.

Another difficulty raised by this constitutive law is the choice of the mechanical parameters $c$ (cohesion) and $\varphi$ (friction angle) of the Mohr-Coulomb criterion. Some methods have been proposed [13] to obtain these parameters for concrete structures. In this study, the values of $c$ and $\varphi$ are proposed in such a way as to respect the Mohr-Coulomb criterion:

$$
\frac{\sigma_{c}}{\sigma_{t}}=\frac{1+\sin \varphi}{1-\sin \varphi} \quad \text { and } \quad \sigma_{t}=\frac{2 c \cos \varphi}{1+\sin \varphi}, \quad \sigma_{c}=-\frac{2 c \cos \varphi}{1-\sin \varphi}
$$

where $\sigma_{t}$ and $\sigma_{c}$ are the tensile and compressive elastic limits of the material, respectively. With this approach, we obtain the values shown in Tables 4 . It is worth noting that the values obtained for $c$ and $\varphi$ do not have much physical significance.

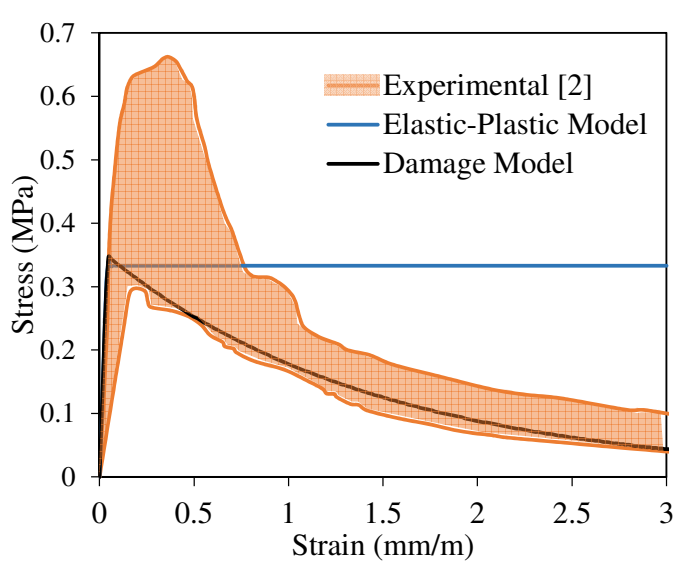

a) Uniaxial tensile test for concrete (see Tables 4)

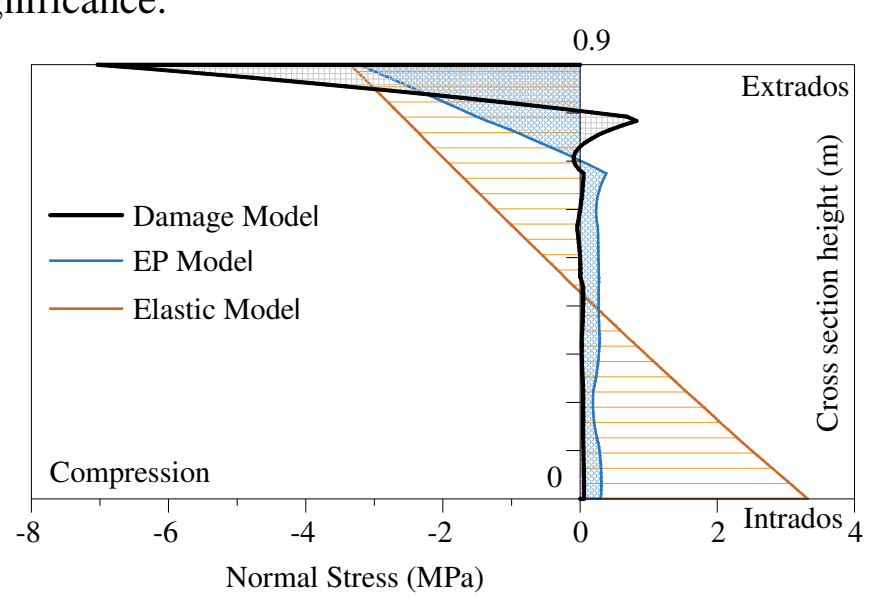

b) Normal stress at the crown crack (see Figure 7)

Figure 10: Stress relations for different constitutive laws for the masonry

Modeling results are shown in Table 3 and Figure 11. We can see that the elastic-plastic model produces a better approximation than the elastic model; however, the convergences are lower than those obtained with the damage model, which are closer to the in-situ measures.

Table 3: Comparison of numerical and measured convergences ( $\mathrm{mm})$

\begin{tabular}{cccc}
\hline Ref. & $\begin{array}{c}\text { Measures } \\
(\mathrm{mm})\end{array}$ & $\begin{array}{c}\text { Damage } \\
\text { Model } \\
(\mathrm{mm})\end{array}$ & $\begin{array}{c}\text { E-P } \\
\text { Model } \\
(\mathrm{mm})\end{array}$ \\
\hline $3-5$ & -54.22 & -54.58 & -40.56 \\
\hline $1-4$ & 19.50 & 18.04 & 12.72 \\
\hline $2-6$ & -18.40 & -22.48 & -16.96 \\
\hline
\end{tabular}

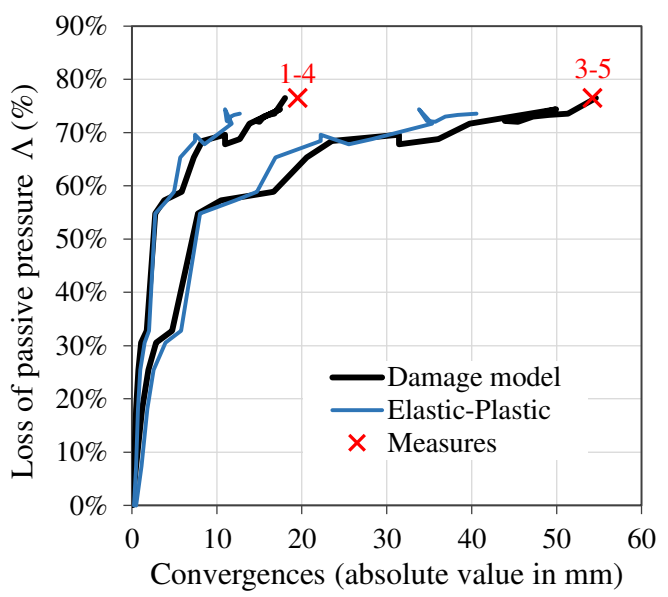

Figure 11: Evolution of the deformation of the structure 


\section{CONCLUSIONS}

We carried out a study on a masonry tunnel of the Paris metro, whose equilibrium state was altered by nearby construction works. A specific damage model for the masonry and concrete was used in the numerical simulations. Given the set of assumptions taken in this study and after analysis of the results, we can conclude the following:

- $\quad$ The proposed model for the tunnel structure reproduces accurately the deformations and cracks in the structure (vertical convergence of about $54 \mathrm{~mm}$ );

- The model shows the formation of a hinge mechanism in the tunnel when the spread of the vault's supports is close to a critical value (about $20 \mathrm{~mm}$ ): three hinges appear in the masonry vault and three in the ground slab.

- From a simplified analytical analysis, we can see that significant deformations and cracks appear in the tunnel when the resistance from the ground available to balance the vault's thrust is reduced by about $50 \%$;

- In all cases, when evaluating numerically the tunnel deformations, a non-linear constitutive law must be used for the tunnel structure; it is clear that an elastic analysis, even with a low elastic modulus, will underestimate the tunnel deformation.

- $\quad$ An elastic-plastic model for the masonry can give better results, but still underestimates the deformations. Also, the constitutive law is not that of the masonry or concrete. The Damage Model is shown to give the best results.

- When performing an elastic analysis, we can see that the most unfavorable case for the displacements is not necessarily the most unfavorable for the internal forces.

Finally, it is worth noting that the setup of a numerical model involving several nonlinear behaviors (masonry, soil and interface) without numerical instabilities remains a very timeconsuming task: further improvements of the numerical tools are highly desirable.

\section{REFERENCES}

[1] Moreno Regan, O. Study of the behavior of the masonry tunnels of the Paris subway system (in French): PhD Thesis, Univ Paris Est, (2016).

[2] Moreno Regan, O., Colas, A., Bourgeois, E., Chatellier, P., Desbordes, A., \& Douroux, J. Experimental characterization of the constitutive materials composing an old masonry vaulted tunnel of the Paris subway system. International Journal of Architectural Heritage Vol. 12(2) (2018), 195-215.

[3] Moreno Regan, O., Bourgeois, E., Colas, A., Chatellier, P., Desbordes, A., \& Douroux, J. Application of a coupled homogenization-damage model to masonry tunnel vaults. Computers and Geotechnics Vol. 83 (2017), pp. 132-141.

[4] Le Bras A. Désordres dans un ouvrage voute de grande ouverture. Démarche suvie pour l'établissement du diagnostic techniques utilisées pour le renforcement. Tunnels et Ouvrages Souterrains, no. 113, pp. 229-303, Septembre/Octobre (1992).

[5] AFTES. The convergence-confinement method (GT7R6A1). Tunnels et Ouvrages Souterrains, no. 174, pp. 414-424 (2002).

[6] Panet, M. Le calcul des tunnels par la méthode convergence-confinement. Presses de l'école nationale des Ponts et chaussées (1995).

[7] Zucchini, A. and Lourenço, P.B. A micro-mechanical model for the homogenisation of masonry," International Journal of Solids and Structures, vol. 39, pp. 3233-3255 (2002). 
[8] Zucchini, A. \& Lourenço, P.B., A coupled homogenisation-damage model for masonry cracking. Computers and Structures, Vol. 82 (11-12), pp.917-29, (2004).

[9] Mazars, J. A description of micro- and macroscale damage of concrete structures. Engineering Fracture Mechanics, vol. 25, pp. $729-737$ (1986).

[10] AFTES. The use of plain concrete in tunnels (GT7R5A1). Tunnels et Ouvrages Souterrains, no. 158 (2000).

[11] NF EN 1997-1. Eurocode 7: Geotechnical design Part 1: General rules (2005).

[12] NF P94-282. Calcul géotechnique Ouvrages de soutènement Écrans (2009).

[13] Hadzijanev Ardiaca, D. Mohr-Coulomb parameters for modelling of concrete structures. Plaxis Bulletin. Spring issue 2009

\section{APPENDIX A}

In the tables presented in this appendix, the following notations are used:

$\rho$ Density

$\gamma \quad$ Soil density

$\gamma^{\prime}$ Effective soil density

E Young's modulus

$v$ Poisson's ratio

$f_{\mathrm{t}} \quad$ Tensile strength

$G_{\mathrm{ft}}$ Mode I fracture energy $f_{\mathrm{c}}$ Compression strength

$A_{\mathrm{c}}$ Damage model coefficient for compression

$B_{\text {c }}$ Damage model coefficient for compression

$\varepsilon_{\text {D0 }}$ Damage threshold strain

$c$ Cohesion

$\varphi \quad$ Friction angle

$\psi$ Dilatancy angle

Tables 4: Material properties

\begin{tabular}{rcccccc}
\hline \multicolumn{7}{c}{ Soil Layers } \\
\hline & Backfill & $\begin{array}{c}\text { Loamy } \\
\text { scree }\end{array}$ & Limestone & Clay & Marls & Chalk \\
\hline$\gamma\left(\mathrm{kN} / \mathrm{m}^{3}\right)$ & 18 & 20 & 21 & 20 & 21 & 21 \\
\hline$\gamma^{\prime}\left(\mathrm{kN} / \mathrm{m}^{3}\right)$ & 8 & 10 & 11 & 10 & 11 & 11 \\
\hline$E^{\prime}(\mathrm{MPa})$ & 20 & 250 & 650 & 38 & 43 & 280 \\
\hline$v$ & 0.333 & 0.333 & 0.333 & 0.333 & 0.333 & 0.333 \\
\hline$c^{\prime}(\mathrm{kPa})$ & 15 & 55 & 35 & 20 & 15 & 40 \\
\hline$\varphi^{\prime}\left({ }^{\circ}\right)$ & 30 & 39 & 32 & 16 & 32 & 35 \\
\hline$\psi\left({ }^{\circ}\right)$ & 0 & 9 & 2 & 0 & 2 & 5 \\
\hline$K_{\mathrm{p}}$ & & 3.2546 & & & \\
\hline
\end{tabular}

\begin{tabular}{|c|c|c|c|c|}
\hline \multicolumn{4}{|c|}{ Tunnel Mate rials [2] } & \multirow{5}{*}{$\begin{array}{l}\text { Elastic } \\
\text { parameters }\end{array}$} \\
\hline & Mortar $^{(1)}$ & $\begin{array}{l}\text { Meulière } \\
\text { stone }^{(1)}\end{array}$ & Concrete & \\
\hline$\rho\left(\mathrm{kN} / \mathrm{m}^{3}\right)$ & 20.08 & 20.58 & 21.60 & \\
\hline$E(\mathrm{MPa})$ & 6000 & 36000 & 8500 & \\
\hline$v$ & 0.15 & 0.30 & 0.21 & \\
\hline$f_{\mathrm{t}}(\mathrm{MPa})$ & 0.300 & 3.440 & 0.350 & \multirow{3}{*}{$\begin{array}{l}\text { Strength } \\
\text { parameters }\end{array}$} \\
\hline$f_{\mathrm{c}}(\mathrm{MPa})$ & 20.0 & 25.0 & 16.0 & \\
\hline$G_{\mathrm{ft}}(\mathrm{Pa} \cdot \mathrm{m})$ & 150 & 121 & 250 & \\
\hline$A_{\mathrm{c}}$ & 1.1 & 1.1 & 1.8 & \multirow{3}{*}{$\begin{array}{l}\text { Damage } \\
\text { parameters, } \\
\text { see [3] and [9] }\end{array}$} \\
\hline$B_{\mathrm{c}}$ & 585 & 1500 & 1174 & \\
\hline$\varepsilon_{\mathrm{D} 0}$ & $5 \times 10^{-5}$ & $9.56 \times 10^{-5}$ & $4.12 \times 10^{-5}$ & \\
\hline
\end{tabular}

(1)The considered size for the components of the masonry for this study is: mortar joints of $70 \mathrm{~mm}$ thickness and meulière stone of $75 \mathrm{~mm}$ and 350 mm of height and width, respectively.

Final properties of the soil layers subjected to creep

\begin{tabular}{ccccc}
\hline Soil layer & $c(\mathrm{kPa})$ & $\varphi\left(^{\circ}\right)$ & $E^{\prime}(\mathrm{MPa})$ & $v$ \\
\hline Limestone & 8.5 & 8.6 & 20 & 0.01 \\
\hline Clay & 15 & 12.1 & 20.5 & 0.18 \\
\hline
\end{tabular}

(3) Properties of the interface (clay and limestone right sidewall) are also subjected to creep.
Material properties for the Elstic-Plastic model

\begin{tabular}{cccc}
\hline & $c(\mathrm{kPa})$ & $\varphi\left({ }^{\circ}\right)$ & $E(\mathrm{MPa})$ \\
\hline Masonry & 1466 & 77.85 & 12400 \\
\hline Concrete & 1183 & 73.174 & 8500 \\
\hline
\end{tabular}

$$
\begin{aligned}
E_{i} & =50 E_{\text {Soil }} \\
c_{\mathrm{i}} & =\frac{c_{\text {soil }} \tan (\delta)}{\tan \left(\varphi_{\text {soil }}\right)}
\end{aligned}
$$

\begin{tabular}{|c|c|c|c|}
\hline \multicolumn{2}{|c|}{ Tie-rods ${ }^{(2)}$} & \multicolumn{2}{|c|}{ Micropiles $^{(2)}$} \\
\hline$\varnothing(\mathrm{mm})$ & 36 & $\varnothing_{\text {int }}$ & 127 \\
\hline$E(\mathrm{MPa})$ & 210000 & $\varnothing_{\text {ext }}$ & 109 \\
\hline Spacing & $2.21 \mathrm{~m}$ & $\mathrm{E}(\mathrm{MPa})$ & 205000 \\
\hline Pre-setress & $650 \mathrm{kN}$ & Spacing & $1.0 \mathrm{~m}$ \\
\hline
\end{tabular}

